\title{
$\sqrt{ }$ |
}

\section{ENGINEERING/TECHNOLOGY}

\section{Analyzing Peer Assessment Claims for Team Projects in Engineering Courses}

Student researcher: Ryan R. Senkpeil, Senior

Ten distinct claims about peer assessment system user perceptions or actions have been made by researchers regarding peer assessments in a team-based project. Over 14,000 raw, verbatim comments were taken from the peer review system, CATME (Comprehensive Assessment of Team Member Effectiveness), a Purdue research initiative sponsored by NSF grant 0817403 . These were then reduced to 8,000 usable comments with all identifying information removed, and sorted into 9 major categories. Each comment was analyzed and was mapped to the most relevant claims it supported. Two of the claims, "Free Riders" and "Missing Skills," were strongly supported by the verbatim comments. "Free Riders" are team members that do not contribute to the team or contribute significantly less than other team members, and "Missing
Skills" is the presence of a team member that does not have the necessary skills or abilities to make a meaningful contribution to the team. From this analysis we concluded that for written comments added voluntarily to a peer review, issues regarding team interactions evoke the strongest response from students. We also discovered that multiple peer reviews of team members over the course of a semester can identify the presence of "Free Riders" or "Missing Skills" earlier and allow instructors to react faster to these potential teaming issues.

Research advisor Daniel Ferguson writes, "Peer reviews are a frequently used and critical teaching tool for students learning and practicing teamwork. Examining the written comments accompanying peer reviews was found to identify two significant teaming issues, Free Riders and Missing Skills. Faculty who examine the written comments in peer reviews can mitigate these two problems."

Senkpeil, R. R. (2014). Analyzing peer assessment claims for team projects in engineering courses. Journal of Purdue Undergraduate Research, 4, 83. http://dx.doi.org/10.5703/1288284315449 